\title{
RELAÇÃO DA IMPORTÂNCIA DOS RECURSOS ESTRATÉGICOS COM AS MEDIDAS DE DESEMPENHO EM EMPRESAS BRASILEIRAS
}

\section{RESUMO}

O estudo objetiva verificar se as medidas de desempenho são variáveis mediadoras entre a importância dos recursos estratégicos e a avaliação de desempenho em empresas brasileiras. De modo específico o estudo busca investigar a percepção dos gestores quanto à importância atribuída às medidas de desempenho tradicionais e não tradicionais e aos recursos estratégicos de capital humano, estrutural e físico em empresas brasileiras. No estudo replica-se a pesquisa realizada por Widener (2006) em empresas norte-americanas. Assim, um levantamento foi realizado junto aos gestores das empresas listadas na BM\&FBovespa nos níveis 1 e 2 de Governança Corporativa. Na análise dos dados foi aplicada estatística descritiva e análise fatorial. Os resultados mostram que os gestores atribuem importância à várias medidas de desempenho, mas a estatística descritiva evidencia que a maior importância é atribuída às medidas de retorno e financeiras tradicionais. Dentre os recursos estratégicos, o capital humano desponta como o recurso mais importante para as empresas analisadas, seguido do capital estrutural e do capital físico. A partir das relações estabelecidas na pesquisa, conclui-se que as medidas de desempenho são variáveis mediadoras entre a importância dos recursos estratégicos e a avaliação de desempenho na percepção dos gestores, o que coaduna com os resultados da pesquisa de Widener (2006) em empresas norte-americanas.

Palavras-chave: Recursos Estratégicos; Indicadores de Desempenho; Gestores; Empresas Brasileiras.

\section{RELATIONSHIP BETWEEN THE IMPORTANCE OF STRATEGIC RESOURCES AND PERFORMANCE MEASURES IN BRAZILIAN COMPANIES}

\section{ABSTRACT}

The goal of the study is to verify whether the performance measures are mediating variables between the importance of strategic resources and performance evaluation in Brazilian companies. Specifically, the study investigates the perceptions of managers regarding the importance of traditional and nontraditional performance measures and human capital, structural and physical strategic resources in Brazilian companies. In the study is replicated the research conducted by Widener (2006) in North American companies. Thus, a survey was conducted with the managers of the companies listed in BM\&FBovespa at levels 1 and 2 of Corporate Governance. Descriptive statistics and factor analysis were applied in data analysis. The results show that managers attribute importance to various performance measures, but the descriptive statistics shows that the greatest importance is attributed to traditional return and financial measures. Among the strategic resources, human capital stands as the most important resource for companies analyzed, followed by structural capital and physical capital. From the relations established in the research, it is concluded that the performance measures are mediating variables between the importance of strategic resources and performance evaluation, in the perception of managers, which is consistent with the search results of Widener (2006) in North American companies.

Keywords: Strategic Resources; Performance Indicators; Managers; Brazilian Companies. 
Relação da Importância dos Recursos Estratégicos com as Medidas de Desempenho em Empresas Brasileiras

\section{IMPORTANCIA DE LA RELACIÓN DE LOS RECURSOS ESTRATÉGICOS MEDIDAS DE RENDIMIENTO EN BRASILEÑO}

\section{RESUMEN}

El estudio tiene por objeto verificar que las medidas de rendimiento son variables mediadoras entre la importancia de los recursos estratégicos y la evaluación del rendimiento en las empresas brasileñas. En concreto, el estudio tiene como objetivo investigar la percepción de los gerentes con respecto a la importancia que se concede a las medidas de rendimiento tradicionales y los recursos no tradicionales y estratégicos de capital humano, estructural y física en las empresas brasileñas. En el estudio se replica la encuesta realizada por Widener (2006) en las empresas estadounidenses. Por lo tanto, se realizó una encuesta con los gerentes de las empresas en la BM \& FBovespa en los niveles 1 y 2 de Gobierno Corporativo. En el análisis de los datos fue la estadística descriptiva y el análisis factorial aplicado. Los resultados muestran que los directores dan importancia a diversas medidas de rendimiento, pero las estadísticas descriptivas muestra la gran importancia que se atribuye a las medidas de retorno y financiero tradicional. Entre los recursos estratégicos, el capital humano surge como el recurso más importante para las empresas analizadas, seguido por el capital estructural y capital físico. A partir de las relaciones establecidas en la investigación, se concluye que las medidas de rendimiento están mediando entre las variables de la importancia de los recursos estratégicos y la evaluación del desempeño en la percepción de los directivos, lo cual es consistente con los resultados de búsqueda de Widener (2006) en las empresas de Estados Unidos.

Palabras clave: Recursos Estratégicos; Los Indicadores de Rendimiento; Gerentes; Las Empresas Brasileñas.

\footnotetext{
${ }^{1}$ Doutora em Controladoria e Contabilidade pela Universidade de São Paulo - USP. Professora da Universidade Federal de Santa Catarina - UFSC. Brasil. E-mail: ilse.beuren@gmail.com

${ }^{2}$ Mestre em Ciências Contábeis pela Universidade Regional de Blumenau - FURB.Professor e coordenador do Curso de Ciências Contábeis na Universidade Paranaense - UNIPAR. Brasil. E-mail: idairmarcello@ unipar.br
} 


\section{INTRODUÇÃO}

As organizações buscam a máxima eficiência com os menores custos possíveis. Os recursos estratégicos das empresas alicerçam esta busca, visando o melhor desempenho organizacional. As medidas de desempenho são utilizadas para obter melhores resultados operacionais e são fundamentais para a avaliação de desempenho organizacional.

Kaplan e Norton (2006) argumentam que avaliar o desempenho das organizações não é tarefa fácil. Advertem que as empresas necessitam de mecanismos de avaliação empresarial para melhor compreender o cenário financeiro e econômico e verificar se as metas estão sendo atingidas. A gestão empresarial é fragilizada sem o uso de medidas de desempenho. A consequência disso é que a administração de uma organização não se torna capaz de avaliar, comparar e corrigir o desempenho sem relatórios que contenham informação apropriada e significativa sobre esse desempenho (Phatak, 1995).

Do ponto de vista da utilização prática dos métodos de avaliação de desempenho organizacional, Salterio e Webb (2003) afirmam que aproximadamente $50 \%$ das empresas que faziam parte de uma relação das mil maiores empresas mundiais da revista Fortune utilizavam algum tipo de metodologia de avaliação de desempenho (Corrêa \& Hourneaux, 2008). Isto demonstra a importância atribuída à mensuração do desempenho empresarial, como forma de verificar se os objetivos traçados estão sendo alcançados.

Em pesquisa realizada pela empresa de consultoria KPMG com 143 altos executivos dos setores público e privado, foi constatado que $93 \%$ deles acreditam que a mensuração é eficiente em influenciar o desempenho da sua organização, mas apenas $51 \%$ encontram-se satisfeitos com os seus atuais sistemas de avaliação de desempenho (Drickhamer, 2002). O autor ressalta que os métodos de mensuração e avaliação de desempenho organizacional tem sido objeto de poucas pesquisas, em especial no que tange a sua real utilidade e eficácia, requisitos fundamentais para a aceitação dos sistemas nas empresas.

Sem que haja uma avaliação de desempenho adequada, os gestores podem encontrar dificuldades para comunicar suas expectativas aos subordinados; saber o que de fato se passa na organização; identificar as falhas, analisá-las e eliminá-las; fornecer feedbacks; identificar o desempenho que deve ser recompensado; e ter um processo decisório baseado em informações efetivas (Rummler \& Brache, 1994). O desempenho pode ser avaliado a partir dos recursos estratégicos das empresas, como os investimentos alocados em determinado capital, por exemplo, o capital humano, o estrutural ou o físico.

Widener (2006) investigou a relação entre a percepção dos gestores sobre a importância dos vários tipos de medidas de desempenho e a importância dos recursos estratégicos da empresa que sustentam sua vantagem competitiva. Além disso, pesquisou se as medidas de desempenho são variáveis mediadoras, na relação entre recursos estratégicos e avaliação de desempenho. Usando dados de 107 empresas, os resultados indicaram que os gestores atribuem importância para várias medidas de desempenho, e que há fortes evidências de que as medidas de desempenho são variáveis mediadoras entre a importância dos recursos estratégicos e a avaliação de desempenho.

Neste estudo replica-se a pesquisa de Widener (2006) em empresas brasileiras, considerando as mesmas medidas de desempenho e recursos estratégicos na avaliação do desempenho. A questão de pesquisa que se apresenta é: As medidas de desempenho são variáveis mediadoras entre a importância dos recursos estratégicos e a avaliação de desempenho em empresas brasileiras? $\mathrm{O}$ estudo objetiva verificar se as medidas de desempenho são variáveis mediadoras entre a importância dos recursos estratégicos e a avaliação de desempenho em empresas brasileiras. De modo específico o estudo busca investigar a percepção dos gestores quanto a importância atribuída às medidas de desempenho tradicionais e não tradicionais e aos recursos estratégicos de capital humano, estrutural e físico em empresas brasileiras.

$\mathrm{O}$ estudo base investiga cinco diferentes tipos de medidas de desempenho (empregado, operacional, produtividade, retorno e financeiras). Essa abordagem pode proporcionar perspectivas diferentes do que as previstas por estudos anteriores, que geralmente investigam a dicotomia entre medidas financeiras versus não financeiras. A premissa é que nas medidas de desempenho coexistem diferentes tipos de indicadores, os quais devem ser elementos capazes de colaborar para o alcance dos objetivos estratégicos propostos pela organização.As justificativas para a realização deste estudo são as mesmas explicitadas na pesquisa replicada. Primeiro, a importância conferida aos recursos intelectuais tem aumentado na atual economia, por este motivo, estudar esses recursos é de grande valia (IFAC, 1998; Lev, 2001). Segundo, a associação da importância dos recursos estratégicos com a avaliação de desempenho pode resultar em insights e implicações importantes para os controllers e a medição de desempenho. Acrescenta-se, neste estudo, a relevância de replicar a pesquisa em um ambiente distinto do estudo base, ou seja, em que medida os resultados da pesquisa em empresas brasileiras se assemelham aos obtidos nas empresas norteamericanas investigadas.

\section{REFERENCIAL TEÓRICO}

\subsection{Recursos estratégicos}

Reportando-se a fases históricas evolutivas, passou-se de uma economia industrial, atrelada ao 
capital físico, para uma economia baseada no capital intelectual (Kaplan \& Norton, 1996; IFAC, 1998; Stivers, Covin, Hall, \& Smalt, 1998; Lev, 2001). A capacidade das empresas de aplicar conhecimentos em recursos de aprendizagem e distribuição da informação tornou-se vital para a obtenção de vantagem diferencial (Hunt, 2000).

Neste contexto emerge a teoria baseada em recursos estratégicos. Barney (1991) define recursos estratégicos como elementos tangíveis e intangíveis que são idiossincráticos nas organizações, difíceis e caros para imitar, heterogêneos, imperfeitamente móveis, valiosos e raros. Hughes e Morgan (2008) esclarecem que esses recursos são insumos essenciais para a estratégia organizacional e determinam sua capacidade para competirem no mercado. Pedrosa e Carvalho (2014) advertem que a vantagem competitiva tem um importante papel nos processos de exploração da combinação de recursos com capacidades.

Os recursos estratégicos são fundamentais para a obtenção de vantagem competitiva das empresas (Luo, Sivakumar, \& Liu, 2005) e incluem a propriedade intelectual, aprendizagem organizacional, clareza de canais de compartilhamento de informações, relacionamentos, compromissos, habilidades empreendedoras, habilidades de implementação, marcas e reputação (Bharadwaj, Varadarajan, \& Fahy, 1993; Barney, 2001). Vasconcelos (2000) define a busca pela vantagem competitiva como sendo "um atributo de posicionamento, exterior à própria organização, derivado da estrutura da indústria, da dinâmica da concorrência e do mercado".

Amit e Schoemaker (1993) identificaram três tipos de possíveis recursos estratégicos: a) Capital Físico, tal como localização geográfica e outros ativos fixos (Barney, 1991); b) Capital Estrutural, que é o conhecimento que foi capturado pela empresa e incorporado na organização por meio de rotinas organizacionais, práticas, processos, novas tecnologias e patentes/licenças (Amit \& Schoemaker, 1993); e c) Capital Humano, que inclui o conhecimento e habilidades (Barney, 1991; Amit \& Schoemaker, 1993).

O capital físico refere-se ao ativo tangível pertencente à empresa (Barney, 1991). Para Coleman (1988), o capital físico é criado por mudanças no desenvolvimento de ferramentas que facilitam a produção. $\mathrm{O}$ autor observa que o capital físico é totalmente tangível, sendo incorporado em formas materiais observáveis.

O capital estrutural é descrito por Edwards (1997) como sendo o conhecimento que foi capturado e convertido em sistemas e recursos de propriedade da empresa. Stewart (1998) pontua como sendo a transformação do conhecimento das pessoas em um ativo da organização, por meio de uma melhoria contínua e do compartilhamento da criatividade e da experiência, que devem ser estruturados com a ajuda da tecnologia da informação, a fim de reter o conhecimento humano.

O capital humano é definido por Edvinsson e Malone (1998), como a capacidade, conhecimento, habilidade e experiência individual dos funcionários de uma organização para a realização de suas tarefas. Para Schultz (1962), considera-se como o capital oferecido aos seres humanos, na valorização da saúde e educação profissional. O conceito de capital humano consiste em atribuir um valor ao capital incorporado nos seres humanos, fruto da sua experiência, educação, formação e know-how (Paiva, 2001).

Tanto o capital humano quanto o capital estrutural são considerados capitais intelectuais. Um recurso intelectual é definido como "o resultado final de um processo de transformação do conhecimento ou o conhecimento que é transformado em propriedade intelectual ou ainda, capital intelectual da empresa" (IFAC, 1998, p. 3). O capital intelectual incorporado no estado da arte da tecnologia e de novas instalações é uma fonte crescente de capital estratégico para as organizações.

A estratégia do capital humano é vista como a chave para o sucesso, posto ser primordial na relação empresa-cliente (Widener, 2006). Quando se investe em capital humano, garante-se tanto o crescimento para o funcionário quanto para o progresso organizacional, uma vez que organizações que investem em treinamento, educação, desenvolvimento e pesquisa estão naturalmente à frente de seus concorrentes, pois souberam armazenar aprendizagens, conhecimentos e experiências.

A visão baseada em recursos estratégicos sustenta que as empresas avaliam os pontos fortes e fracos de seus recursos e suas capacidades subjacentes para depois selecionar uma estratégia que lhe é possível (Widener, 2006). Para Amit e Shoemaker (1993), os recursos estratégicos proporcionam à empresa a base para a vantagem competitiva sustentada. Assim, é fundamental que os gestores sejam capazes de medir a eficiência e eficácia desses recursos e gerar feedback sobre seu desempenho.

Pedrosa e Carvalho (2014, p. 10) testaram em estudo empírico "se as combinações de recursos e capacidades com valor, raridade e inimitabilidade, mais do que a sua especificidade, determinam maior vantagem competitiva e performance". Os resultados compilados de 368 questionários respondidos por gestores de empresas portuguesas indicaram que o aumento do valor, da raridade e da inimitabilidade das combinações testadas eleva a vantagem competitiva da empresa, o que se reflete na performance.

\subsection{Medidas de desempenho}

O interesse pela medição de desempenho cresceu a partir dos anos 1990, especialmente com discussões sobre a inclusão de medidas não-financeiras na avaliação de desempenho (Sellitto, Borchardt, \& Pereira, 2006). Gonçalves (2002) ressalta que todas as 
empresas necessitam de um sistema de avaliação de desempenho, uma vez que a realização contínua do processo de avaliação permite que a empresa conheça a eficiência e a eficácia de suas ações, bem como o comportamento das pessoas, os processos e os programas da organização.

Para Callado, Callado, Moller e Neutzling (2009), as medidas de desempenho são elementos fundamentais para a mensuração de performance, bem como na definição das variáveis que melhor representem o desempenho geral de uma empresa. Para Beyan e Baykal (2012), as medidas de desempenho examinam as funcionalidades de um sistema a partir de medidas de partes de seus processos, por meio de indicadores de desempenho que fornecem informações indiretas, mas contribuem para a identificação do seu desempenho global.

MacArthur (1996) conceitua medidas de desempenho como sendo a quantificação de como estão sendo realizadas as atividades com o propósito de comparar com as metas especificadas. Sobre o papel das medidas de desempenho no processo gerencial das organizações, Martins (2004) afirma que o processo de gestão de desempenho é o meio pelo qual uma organização administra seu desempenho de acordo com as estratégias corporativas e funcionais, bem como seus objetivos.

As medidas de desempenho dão aos gestores as informações necessárias para gerir adequadamente seus negócios e os recursos estratégicos. Muller (2003) enfatiza que um sistema de avaliação de desempenho "deve induzir nos processos da empresa seus objetivos e estratégias, constituindo os elos entre os objetivos e a execução prática das atividades nas empresas". Para Neely (1995), a análise e a medida de desempenho podem ser definidas como o processo de se quantificar uma ação, no qual mensuração é o processo de quantificação da eficiência e eficácia e a ação é aquilo que provoca o desempenho.

Porém, não basta a simples criação de indicadores de desempenho, sem realizar um acompanhamento dessas medidas tendentes para obter uma a eficácia do sistema. $O$ objetivo do gerenciamento do desempenho organizacional é garantir que a organização, com todos os seus subsistemas (processos, departamentos, colaboradores), trabalhe sincronizada para que os resultados positivos possam surgir (Godoy, 2009).

As empresas utilizam tanto de medidas tradicionais quanto de medidas não tradicionais na avaliação de desempenho (Kaplan \& Norton, 1996). As medidas tradicionais são as informações financeiras agregadas e derivadas das demonstrações financeiras e dos orçamentos, que incluem medidas como lucro líquido, retorno sobre ativos e variações orçamentárias (Ittner \& Larcker, 1995). Essas medidas não fornecem informações sobre o desempenho futuro, bem como sobre as capacidades intelectuais e os recursos que muitas empresas estão utilizando em suas atividades econômicas (Kaplan \& Norton, 1996; Simons, 2000;
Lev, 2001).

De acordo com Bourne, Neely, Mills, Platts e Wilcox (2000) e Kennerly e Neely (2003), tais medições acarretam, entre outros problemas: a) falta de informação sobre o desempenho futuro; b) enfoque em otimizações locais e de curto prazo; c) perda de alinhamento com estratégias mais elaboradas de produção; d) pouca informação para decisões em ambientes turbulentos.

As informações não tradicionais incluem as medidas orientadas diretamente às operações da empresa e aos objetivos estratégicos (Ittner \& Larcker, 1995). Os custos de qualidade, formação e produtividade dos funcionários são exemplos de medidas financeiras não tradicionais; enquanto que a satisfação dos clientes e a satisfação dos empregados são exemplos de medidas não financeiras e não tradicionais (Widener, 2006).

A fim de controlar os fatores críticos de sucesso em empresas, os sistemas de medição de desempenho precisam englobar várias medidas (Kaplan \& Norton, 1996; IFAC, 1998). Neste sentido, as empresas podem implementar sistemas como o Balanced Scorecard, que inclui medidas de ampla gama de atividades da empresa (Widener, 2004; 2006).

Os pressupostos do Balanced Scorecard e de outros sistemas de medição de performance estratégica são de que é importante acompanhar as medidas financeiras para assegurar que a realização de medidas não financeiras afetem o desempenho da empresa (Kaplan \& Norton, 1996). No entanto, as medidas financeiras por si só não são suficientes para gerir o capital humano. Pode acontecer que essas medidas motivem os gestores a tomar decisões que não são saudáveis para a empresa no longo prazo (Lev, 2001).

As empresas que dependem de capital estrutural associam a avaliação de desempenho com a inovação, arte e novas tecnologias. As medidas financeiras tradicionais de informação não são suficientes para as empresas que se utilizam de tecnologia avançada, já que as medidas financeiras são de curto prazo (Widener, 2006). Para a gerência do capital físico, as empresas dependem fortemente de medidas financeiras tradicionais, como monitoramento de retorno sobre ativos e lucratividade (Kaplan \& Norton, 1996; Lev, 2001).

Os capitais físicos são registrados no balanço patrimonial das empresas e são controlados e monitorados por meio de medidas financeiras tradicionais (Widener, 2006). As medidas financeiras são normalmente adequadas para controlar a eficiência com que o capital é empregado; comunicar valor para os stakeholders; e fornecer aos gerentes as informações necessárias para alocar capital interno adequado para projetos de capital intensivo (Kaplan \& Norton, 1996).

As pesquisas relativas à importância e aceitação das medidas não financeiras têm evoluído por diferentes caminhos, seja como indicadores de tendências que propiciam informações sobre o desempenho futuro, em que a prática tem demonstrado 
grande dificuldade para relacionar estas medidas com desempenhos contábeis, seja no valor de suas ações no mercado, ou no uso de medidas não-financeiras em planos de remuneração (Brancato, 1995; Ittner \& Larcker, 1996; 1998).

Mia e Clarke (1999) investigaram a associação entre a concorrência no mercado e o desempenho da unidade de negócios e descobriram que a concorrência afeta o desempenho por meio do uso da informação contábil. Eles concluíram que isso acontece porque o uso da informação contábil fornece às empresas um subsídio crítico para se posicionarem corretamente no mercado e assim combaterem as ameaças competitivas (Widener, 2006).

Baines e Langfield-Smith (2003) usaram um modelo para investigar mudanças na contabilidade gerencial. Constataram que mudanças no desenho organizacional, novas tecnologias e práticas de fabricação avançadas impactam positivamente no desempenho organizacional por meio de mudanças nas informações não financeiras de gestão contábil.

Aguiar e Frezatti (2014) investigaram o relacionamento entre o uso de medidas não financeiras de desempenho e a orientação temporal dos gestores de nível intermediário de 11 empresas dentre as 150 listadas no ranking das 'Melhores Empresas para Você Trabalhar', em que obtiveram 70 questionários preenchidos. Os resultados indicaram associação significativa entre uso de medidas não financeiras e orientação temporal dos gestores, mas orientação temporal mais de curto prazo está associada com maior importância atribuída a medidas não financeiras de desempenho. Concluíram que podem existir situações em que o uso de medidas não financeiras de desempenho não contribui para a tomada de decisões de longo prazo.

Beuren, Kaveski e Rigo (2014) verificaram a associação das medidas de desempenho utilizadas no pagamento de bônus aos executivos com a dependência de capital humano e o efeito moderador da estrutura de remuneração em 60 empresas que realizaram pagamento de bônus com base em ações listadas na
BM\&FBovespa. Os resultados indicaram que o uso de medidas não financeiras e de recursos humanos para pagamento de bônus aos executivos nas empresas dependentes de capital humano é maior quando adotam estruturas de remuneração igualitária, do que com estruturas de remuneração hierárquica.

Assim, as empresas constroem um sistema de medição de desempenho para incluir medidas de desempenho que irão fornecer informações essenciais para os gestores em matéria de recursos da empresa e capacidades subjacentes (Simons, 2000). Estas, por sua vez, irão afetar positivamente o desempenho (Kaplan \& Norton, 1996; Lev, 2001).

Considerando-se os estudos enunciados, busca-se verificar se os achados desses autores podem ser verificados em empresas brasileiras. Especial atenção será conferida ao estudo base deste estudo, já que a pesquisa de Widener (2006) será objeto de replicação, por isso o próximo tópico abordará a metodologia adotada e seus resultados.

\subsection{Pesquisa de Widener (2006)}

No desenvolvimento do estudo, Widener (2006) teve como uma das premissas que os gestores avaliam os seus recursos estratégicos e escolhem as medidas de desempenho que estão alinhados com esses recursos, que, por sua vez, afetam o desempenho. Outra premissa foi que na economia atual, o capital estrutural é provavelmente o recurso mais importante para as empresas, enquanto que as funções do capital humano assumem um papel de apoio fundamental. $\mathrm{O}$ capital humano é provavelmente o mais importante recurso estratégico para as empresas e a sua gestão adequada inclui o uso de medidas não tradicionais.

O modelo teórico exposto na Figura 1 ilustra que, embora a importância dos recursos estratégicos tenha uma associação direta e positiva com o desempenho da empresa (H1), a importância de medidas de desempenho vai intervir nessa relação (Widener, 2006). 


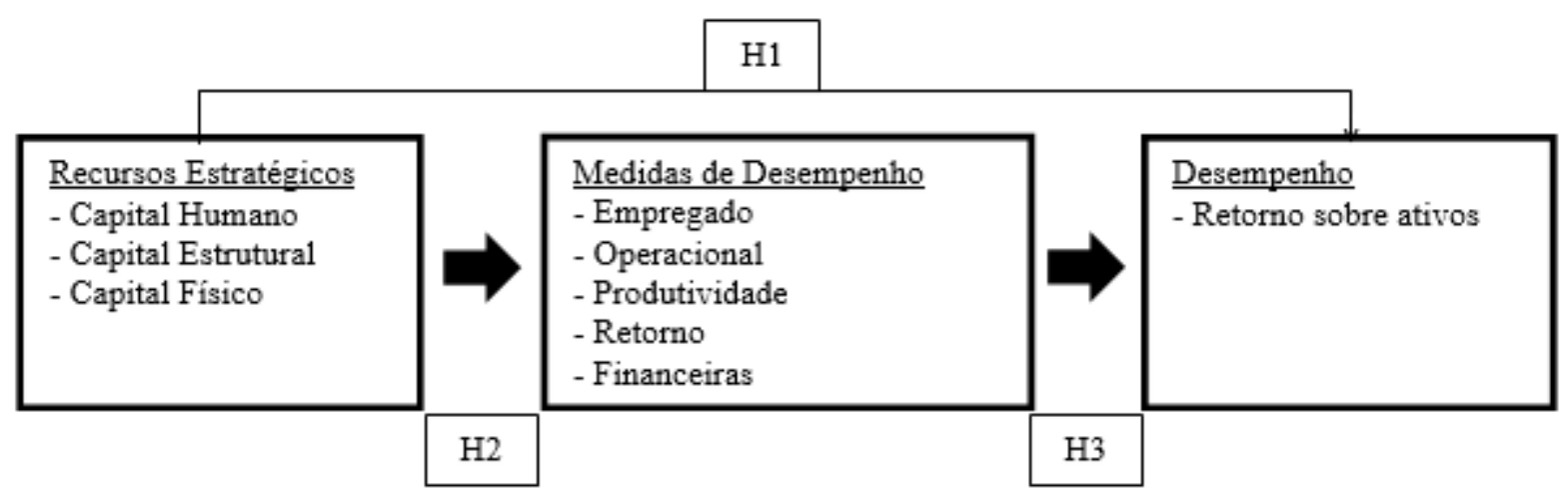

Figura 1 - Modelo teórico

Fonte: Widener (2006, p. 434).

Conforme Figura 1, uma vez que as empresas têm identificados os seus recursos estratégicos, elas irão implementar um sistema de medição de desempenho para ajudar a gerencia-los adequadamente. A seu turno, a partir do fornecimento de feedback crítico, as empresas podem utilizar-se dos recursos estratégicos para aprimorar o desempenho (Widener, 2006). Nesta perspectiva, a autora formulou as seguintes hipóteses de pesquisa:

H1: Há uma associação significativa positiva entre a avaliação dos gestores da importância dada pela empresa aos diversos recursos estratégicos e o desempenho.

H1a: Para empresas não manufatureiras, a associação entre a importância dada ao capital humano e o desempenho é mais forte do que as associações entre a importância atribuída aos outros recursos estratégicos (capital físico e capital estrutural) e o desempenho.

H1b: Para empresas manufatureiras, a associação entre a importância dada ao capital estrutural e humano e o desempenho é mais forte do que a associação entre a importância atribuída aos recursos físicos e o desempenho.

H2: Há uma associação significativa positiva entre a avaliação dos gestores da importância do uso de certos tipos de medidas de desempenho e a sua avaliação da importância dada pela empresa aos diversos recursos estratégicos.

H2a: Há uma associação mais forte entre a avaliação dos gestores da importância dada pela empresa ao capital humano e a sua avaliação da importância do uso de medidas não tradicionais (empregado, produtividade e medidas operacionais), do que com a sua avaliação da importância do uso de medidas tradicionais.

H2b: Há uma associação mais forte entre a avaliação dos gestores da importância dada pela empresa ao capital estrutural e a sua avaliação da importância das medidas não tradicionais (empregado, produtividade e medidas operacionais), do que com a sua avaliação da importância do uso de medidas tradicionais.

H2c: A associação entre a avaliação dos gestores da importância do uso de medidas não tradicionais (empregado, produtividade e medidas operacionais) e sua avaliação da importância dada pela empresa ao capital estrutural é mais forte em empresas manufatureiras do que não manufatureiras.

H2d: Há uma associação mais forte entre a avaliação dos gestores da importância dada pela empresa ao capital físico e sua avaliação da importância do uso de medidas tradicionais, do que com a sua avaliação da importância do uso de medidas não tradicionais (empregado, produtividade e medidas operacionais).

H3: A avaliação dos gestores da importância do uso de medidas de desempenho medeia significativamente a relação entre as crenças dos gestores sobre a importância dos recursos estratégicos e o desempenho da empresa.

H3a: Para empresas não manufatureiras, o mais forte efeito indireto sobre o desempenho é a avaliação dos gestores da importância dada pela empresa ao capital humano, mediada pela avaliação dos gestores da importância do uso de medidas não tradicionais.

H3b: Para empresas manufatureiras, o mais forte efeito indireto sobre o desempenho é a avaliação dos gestores da importância dada pela empresa ao capital estrutural e humano, mediada pela avaliação dos gestores da importância do uso de medidas não tradicionais.

As empresas incluídas na base de dados da autora foram retiradas da Compustat, com uma população de 1.662 empresas, das quais 800 foram aleatoriamente pesquisadas. Como o estudo centrou-se nos recursos estratégicos, empresas altamente diversificadas foram excluídas da amostra. A maior concentração de empresas foi de indústrias (43\%), 
seguida de empresas de serviços financeiros (17\%), outras empresas de serviços (13\%) e transporte, comunicação e serviços públicos $(11 \%)$. Os resultados foram baseados em dados de 107 empresas (14\%), as que retornaram a pesquisa com dados completos para todas as questões utilizadas no estudo.

Widener (2006) utilizou dados de duas perguntas de um inquérito de um estudo mais amplo que investigou o sistema de controle de gestão (Widener, 2004). Esta parte do inquérito constituiu-se de dois blocos de perguntas: Bloco A - Importância do uso de medidas de desempenho; e Bloco B Importância dos recursos estratégicos. A seleção das medidas de desempenho e dos recursos estratégicos foi retirada da literatura básica pesquisada.

No Bloco A, os respondentes foram convidados a indicar a importância de cada medida de desempenho no sistema de informação interno, usando uma escala Likert de 7 pontos, onde 1 correspondia a pouca ou nenhuma importância, e 7 a extrema importância. Foram utilizados na pesquisa 17 indicadores de desempenho. No Bloco B, cada respondente foi convidado a indicar a importância dos recursos estratégicos para a manutenção da vantagem competitiva da empresa em uma escala de 1 a 7 , onde 1 correspondia a muito importante e 7 a pouca importância. Foram utilizados 7 indicadores de recursos estratégicos. No entanto, na análise dos dados do Bloco B foi utilizada a escala reversa para fins de alinhamento com a escala do Bloco A.

Para analisar os dados, inicialmente a autora utilizou-se da análise fatorial. Os fatores foram rodados utilizando a rotação ortogonal parsimax. A análise dos 17 indicadores de desempenho resultou em cinco componentes com autovalores superiores a $1 \mathrm{e}$, juntos, representaram $71 \%$ da variância. Nesta fase dois indicadores foram excluídos: segurança dos empregados, porque apresentou um fator negativo no carregamento com produtividade; e vendas por empregado, porque carregou altamente o quinto fator, ou seja, para garantir a distinção entre os construtos esta questão não foi utilizada na medida final. Por sua vez, a análise dos 7 indicadores de recursos estratégicos resultou em três componentes com autovalores superiores a 1 e, juntos, representaram $68 \%$ da variância.

$\mathrm{Na}$ sequência, a análise dos dados foi direcionada de modo a responder a três hipóteses de pesquisa e as respectivas sub-hipóteses. Os resultados da pesquisa desenvolvida por Widener (2006) foram resumidos e estão transcritos a seguir:

a) os achados mostram que as empresas prestam atenção nos vários tipos de medidas de desempenho. Por exemplo, a avaliação dos gestores da importância dada pela empresa ao capital estrutural está associada positivamente com a sua avaliação da importância do uso de indicadores de produtividade, , operacional, empregado, retorno e financeiros:

b) a avaliação dos gestores da importância dada pela empresa ao capital estrutural é mais fortemente associada com a sua avaliação do uso de medidas não tradicionais do que com medidas tradicionais, embora tenha sinais mistos que a importância atribuída aos recursos físicos é mais fortemente associada com medidas tradicionais do que com medidas não tradicionais;

c) o estudo forneceu evidências de que a avaliação dos gestores da importância dada pela empresa ao uso de medidas de desempenho medeia a relação entre a importância dos recursos estratégicos e o desempenho da empresa.

Como esperado, conforme Widener (2006), os gestores que conferiram importância estratégica ao capital humano, por sua vez, atribuíram maior importância ao uso de medidas não tradicionais (empregado, produtividade, medidas operacionais), e apresentaram um desempenho significativamente superior. Portanto, os resultados mostram que as medidas de desempenho são variáveis mediadoras entre a avaliação dos gestores da importância dada pela empresa aos diversos recursos estratégicos e o desempenho da empresa.

Quanto à percepção dos gestores em relação às medidas de desempenho, os resultados encontrados na pesquisa de Widener (2006) foram os seguintes:

a) os gestores atribuem importância para várias medidas, no entanto, as estatísticas descritivas mostram que a maior importância é atribuída às medidas financeiras tradicionais;

b) embora dêem maior importância às medidas financeiras tradicionais, a importância atribuída às medidas de desempenho não tradicionais é relevante, pois elas são importantes para o desempenho da empresa;

c) as medidas não tradicionais são relevantes até mesmo para as empresas que atribuem importância ao capital físico para sustentar a sua vantagem estratégica.

Estes foram os principais resultados obtidos na pesquisa de Widener (2006) em empresas norteamericanas. Ressalta-se que não foram suportadas as três hipóteses (H1b, H2c e H3b) que indicavam situações diferenciadas para empresas manufatureiras e não manufatureiras. Desse modo, na presente pesquisa replica-se o construto e as hipóteses, exceto as três que não foram suportadas no estudo base, em empresas 
brasileiras. Espera-se, desse modo, que possíveis resultados convergentes ou divergentes possam contribuir para a consolidação do modelo teórico.

\section{METODOLOGIA DA PESQUISA}

Segundo as tipologias de delineamentos de pesquisas citadas por Raupp e Beuren (2006), este estudo classifica-se quanto aos seus objetivos como uma pesquisa descritiva, pois procura descrever a relação existente entre os recursos estratégicos e o desempenho em empresas brasileiras. Quanto aos procedimentos de coleta dos dados, a pesquisa se insere do tipo levantamento ou survey. Este tipo de coleta ocorre por meio da aplicação de questionário numa determinada amostra (GIL, 2002).

Com relação às tipologias de pesquisa para a abordagem do problema o estudo se apresenta como uma pesquisa quantitativa. Diferentemente da pesquisa qualitativa, esta modalidade de pesquisa se utiliza de instrumentos matemáticos, tanto na coleta quanto na análise dos dados. Richardson (1999) afirma que a abordagem quantitativa é caracterizada pelo emprego de quantificação, ou seja, de técnicas desde as mais simples (percentual e médias) às mais complexas (coeficiente de correlação e análise de regressão).

\subsection{Construto da pesquisa}

Neste estudo foi replicado o construto da pesquisa de Widener (2006), em empresas norteamericanas, com algumas adaptações. Como nesta pesquisa não foram segregadas as empresas manufatureiras das não manufatureiras, em função do tamanho da amostra, as hipóteses H1b, H2c e H3b do estudo base não puderam ser testadas. É relevante destacar também que as hipóteses H1b e H3b não foram suportadas e a $\mathrm{H} 2 \mathrm{c}$ foi parcialmente suportada no estudo de Widener (2006). Pelo mesmo motivo, nas hipóteses H1a e H3a foi suprimido o início da frase, que faz distinção para empresas não manufatureiras, tornando-as genéricas para todas as empresas da amostra pesquisada.

Outro aspecto que se difere nesta pesquisa é que Widener (2006) realizou análise fatorial, utilizando a rotação ortogonal parsimax, e encontrou para os indicadores do Bloco A (importância do uso de medidas de desempenho) cinco agrupamentos e para o Bloco B (importância dos recursos estratégicos) três agrupamentos, cujos fatores foram mantidos no presente estudo sem novo teste estatístico. Por conseguinte, os dois fatores, segurança dos empregados e vendas por empregado, eliminados do estudo base pelos motivos já acima apontados, também não foram utilizados nesta pesquisa. No Quadro 1 apresentam-se as medidas de desempenho e os recursos estratégicos, ambos com seus respectivos indicadores.

\begin{tabular}{|c|c|}
\hline $\begin{array}{c}\text { Bloco A } \\
\text { Importância do uso de medidas de desempenho }\end{array}$ & $\begin{array}{c}\text { Bloco B } \\
\text { Importância dos recursos estratégicos } \\
\end{array}$ \\
\hline Empregado (EMP) & Capital humano $(\mathrm{CH})$ \\
\hline $\begin{array}{l}\text { Satisfação dos funcionários } \\
\text { Desenvolvimento de competências dos empregados } \\
\text { Turnover voluntário }\end{array}$ & $\begin{array}{l}\text { Capital humano } \\
\text { Conhecimento dos clientes }\end{array}$ \\
\hline Dias de treinamento por empregado & Capital estrutural (CE) \\
\hline $\mathrm{N}^{\circ}$ de planos de desenvolvimento pessoal concluídos & \multirow{3}{*}{$\begin{array}{l}\text { Estado da Arte/instalações } \\
\text { Novas tecnologias } \\
\text { Patentes e outros tipos de ativos }\end{array}$} \\
\hline Operacional (OP) & \\
\hline $\begin{array}{l}\text { Vendas de novos produtos ou serviços } \\
\text { Ciclo ou lead time }\end{array}$ & \\
\hline Número de patentes & Capital físico (CF) \\
\hline Produtividade (PROD) & \multirow{6}{*}{$\begin{array}{l}\text { Dispersão geográfica das unidades } \\
\text { Outros ativos fixos }\end{array}$} \\
\hline Vendas / custo da mão de obra & \\
\hline Retorno (RET) & \\
\hline $\begin{array}{l}\text { Retorno sobre investimento } \\
\text { Retorno sobre ativos }\end{array}$ & \\
\hline Financeiras (FIN) & \\
\hline $\begin{array}{l}\text { Lucro/Lucro Líquido } \\
\text { Vendas } \\
\text { Variações no Orçamento } \\
\text { Metas Financeiras }\end{array}$ & \\
\hline
\end{tabular}

Quadro 1 - Construto da pesquisa

Fonte: Elaboração própria com base em Widener (2006).

Os elementos do construto foram inseridos no instrumento de pesquisa, em que os respondentes foram convidados a indicar qual a importância de cada um dos 15 indicadores de desempenho no sistema de informação interna da empresa, usando a escala Likert de 5 pontos, onde 1 é de pouca ou nenhuma 
Relação da Importância dos Recursos Estratégicos com as Medidas de Desempenho em Empresas Brasileiras

importância e 5 de extrema importância. Também solicitou-se indicar a importância de cada um dos 7 indicadores de recursos estratégicos para a manutenção da vantagem competitiva da empresa em uma escala de 1 a 5 , onde 1 correspondia a muito importante e 5 a pouca importância. As diferenças na escala, 5 pontos neste estudo e 7 pontos na pesquisa de Widener (2006), decorrem de um lapso de formatação.

\subsection{População e amostra}

Como a proposta deste estudo é replicar a pesquisa de Widener (2006) no Brasil, foram selecionadas para esta investigação as empresas brasileiras listadas na Bolsa de Valores, Mercadorias e Futuros de São Paulo (BM\&FBovespa). Por sua vez, a amostra restringiu-se às empresas brasileiras classificadas nos níveis 1 e 2 de Governança Corporativa (57 empresas). Vale ressaltar que excluíram-se da amostra as instituições financeiras, em função de suas características peculiares.

Das 57 empresas que fizeram parte da amostra, 17 retornaram o questionário respondido (30\% da amostra), constituindo-se em uma amostra por acessibilidade. $\mathrm{O}$ respondente alvo da pesquisa foi $\mathrm{o}$ diretor-executivo financeiro ou o controller de cada empresa, o que coaduna com o critério adotado no estudo base. Destaca-se por oportuno que o baixo número de respostas restringiu o refinamento da análise dos resultados, o que se configura como a principal limitação desta pesquisa.

\subsection{Procedimentos de coleta e análise dos dados}

O questionário para o levantamento foi elaborado na plataforma do Google Docs e enviado para as empresas da amostra via e-mail. $\mathrm{O}$ endereço eletrônico dos respondentes nas empresas da amostra foi obtido por meio de contato telefônico, a partir da listagem de telefones do departamento de relações com investidores das empresas, reportados no site da BM\&FBovespa. Os dados foram coletados nos meses de janeiro a março de 2012.

Os dados coletados foram tabulados a partir dos questionários respondidos pelos gestores das empresas. Para as assertivas do Bloco B, a fim de alinha-las com as assertivas do Bloco A, utilizou-se a escala reversa, ou seja, 1 passou a corresponder a pouco importante e 5 a muito importante. Após isso, os dados foram analisados utilizando-se do software Excel da Microsoft, para as estatísticas descritivas, e o software SPSS v. 18.0, para análise de correlações entre as variáveis propostas. Foi aplicada a correlação de Spearman para verificar a força do relacionamento entre as variáveis, considerando-se cada fator de forma isolada.

Portanto, a análise deste estudo, em função do pequeno número de respondentes do instrumento de pesquisa, difere-se da análise realizada por Widener (2006), que aplicou a modelagem de equações estruturais (Structural Equation Modeling - SEM). Além disso, separou a amostra em empresas manufatureiras e empresas não manufatureiras. Apesar das limitações impostas pelo tamanho da amostra, neste estudo mantiveram-se as hipóteses, exceto as já comentadas, e o construto do estudo base.

\section{DESCRIÇÃO E ANÁLISE DOS RESULTADOS}

O estudo utiliza-se de dois blocos de perguntas. $\mathrm{O}$ primeiro diz respeito às medidas de desempenho e questiona sobre a importância do uso de cada medida como uma característica do sistema de controle de gestão. O segundo refere-se aos recursos estratégicos e questiona qual elemento é mais importante para sustentar a vantagem competitiva da organização no mercado. As pontuações do Bloco B foram invertidas em relação ao estudo original, de modo que uma maior pontuação indica maior importância, o que foi observado naquele estudo apenas na tabulação dos resultados.

\subsection{Análise descritiva}

Na Tabela 1 apresentam-se as medidas de confiabilidade e a estatística descritiva das respostas sobre o grau de importância na percepção dos respondentes, para ambos os blocos de perguntas em escala Likert de cinco pontos.

Tabela 1 - Estatística descritiva e medidas de confiabilidade

\begin{tabular}{|l|c|c|c|c|c|}
\hline & Mín. & Máx. & Média & $\begin{array}{c}\text { Desvio } \\
\text { Padrão }\end{array}$ & $\begin{array}{c}\text { Alfa de } \\
\text { Cronbach }\end{array}$ \\
\hline Bloco A: Importância do uso de medidas de desempenho & & & & & \\
\hline Empregado (EMP) & $\mathbf{1}$ & $\mathbf{5}$ & $\mathbf{3 , 4 8}$ & $\mathbf{0 , 6 2 1}$ & $\mathbf{0 , 7 9}$ \\
\hline Satisfação dos funcionários & 3 & 5 & 4,00 & 0,707 & \\
\hline Desenvolvimento de competências dos empregados & 3 & 4 & 3,41 & 0,507 & \\
\hline Turnover voluntário & 3 & 4 & 3,18 & 0,393 & \\
\hline Dias de treinamento por empregado & 3 & 5 & 4,00 & 0,612 & \\
\hline Número de planos de desenvolvimento pessoal concluídos & 1 & 4 & 2,82 & 0,883 & \\
\hline
\end{tabular}


Relação da Importância dos Recursos Estratégicos com as Medidas de Desempenho em Empresas Brasileiras

\begin{tabular}{|l|c|c|c|c|c|}
\hline Operacional (OP) & $\mathbf{1}$ & $\mathbf{5}$ & $\mathbf{3 , 2 8}$ & $\mathbf{0 , 9 2 8}$ & $\mathbf{0 , 5 3}$ \\
\hline Vendas de novos produtos ou serviços & 2 & 5 & 3,06 & 1,144 & \\
\hline Ciclo ou lead time & 3 & 5 & 4,47 & 0,624 & \\
\hline Número de patentes & 1 & 4 & 2,18 & 1,015 & \\
\hline Produtividade (PROD) & $\mathbf{2}$ & $\mathbf{4}$ & $\mathbf{3 , 4 1}$ & $\mathbf{0 , 8 7 0}$ & N/A \\
\hline Vendas / custo da mão de obra & 2 & 4 & 3,41 & 0,870 & \\
\hline Retorno (RET) & $\mathbf{3}$ & $\mathbf{5}$ & $\mathbf{4 , 5 0}$ & $\mathbf{0 , 7 1 2}$ & $\mathbf{0 , 5 2}$ \\
\hline Retorno sobre investimento & 3 & 5 & 4,59 & 0,712 & \\
\hline Retorno sobre ativos & 3 & 5 & 4,41 & 0,712 & \\
\hline Financeiras (FIN) & $\mathbf{1}$ & $\mathbf{5}$ & $\mathbf{4 , 1 9}$ & $\mathbf{0 , 7 8 7}$ & $\mathbf{0 , 5 7}$ \\
\hline Lucro/Lucro Líquido & 3 & 5 & 4,41 & 0,712 & \\
\hline Vendas & 4 & 5 & 4,59 & 0,507 & \\
\hline Variações no Orçamento & 1 & 5 & 3,59 & 1,121 & \\
\hline Metas Financeiras & 3 & 5 & 4,18 & 0,809 & \\
\hline Bloco B: Importância dos recursos estratégicos & & & & & \\
\hline Capital humano (CH) & $\mathbf{3}$ & $\mathbf{5}$ & $\mathbf{4 , 2 4}$ & $\mathbf{0 , 7 0 4}$ & $\mathbf{0 , 5 6}$ \\
\hline Capital humano & 3 & 5 & 4,29 & 0,772 & \\
\hline Conhecimento dos clientes & 3 & 5 & 4,18 & 0,636 & \\
\hline Capital estrutural (CE) & $\mathbf{1}$ & $\mathbf{5}$ & $\mathbf{3 , 4 7}$ & $\mathbf{1 , 2 0 1}$ & $\mathbf{0 , 6 0}$ \\
\hline Estado da Arte/instalações & 2 & 5 & 3,59 & 1,004 & \\
\hline Novas tecnologias & 2 & 5 & 3,82 & 1,185 & \\
\hline Patentes e outros tipos de ativos & 1 & 5 & 3,00 & 1,414 & \\
\hline Capital físico (CF) & $\mathbf{2}$ & $\mathbf{5}$ & $\mathbf{3 , 2 1}$ & $\mathbf{1 , 1 2 0}$ & $\mathbf{0 , 6 2}$ \\
\hline Dispersão geográfica das unidades & 2 & 5 & 3,41 & 1,121 & \\
\hline Outros ativos fixos & 2 & 5 & 3,00 & 1,118 & \\
\hline
\end{tabular}

Fonte: dados da pesquisa.

Verifica-se na Tabela 1 que o Alfa de Cronbach dos indicadores variou de 0,52 a 0,79. Para Hair Jr, Babin, Money e Samouel (2005), uma variação do coeficiente alfa menor que 0,6 é considerada de baixa intensidade na associação, de 0,6 a $<0,7$ indica uma moderada intensidade e de 0,7 a $<0,8$ uma boa intensidade da associação. Apesar do coeficiente alfa de alguns indicadores estar na faixa de baixa intensidade, o que também ocorreu no estudo de Widener (2006), eles foram mantidos para fins de análise comparativa dos resultados, e pela sua proximidade do mínimo de 0,60. Ressalta-se ainda que Produtividade indicou "N/A" (Não Apurado) para o Alfa de Cronbach, o que também ocorreu no mesmo item no estudo de referência, já que é formado por apenas uma variável.

O Bloco A registra o grupo de indicadores relativos a importância do uso de medidas de desempenho pelas empresas. No indicador Empregado (EMP), os gestores foram questionados sobre a importância atribuída às medidas de desempenho com relação aos empregados, em específico quanto a satisfação dos empregados, desenvolvimento de competências dos empregados, turnover voluntário, dias de treinamento por empregado e número de planos de desenvolvimento pessoal concluídos. No intervalo de 1 a 5, obteve-se uma média de 3,48 e um desvio padrão de 0,621. No indicador Operacional (OP), as perguntas dizem respeito às operações internas da empresa, que incluem vendas de novos produtos e serviços, ciclo ou lead time e número de patentes. No intervalo entre 1 e 5, a média foi de 3,28 e o desvio padrão de 0,928. O indicador Produtividade (PROD) constitui-se de apenas uma pergunta sobre as vendas em relação ao custo da mão de obra. O intervalo foi de 2 e 4 e a média de 3,41 , com desvio padrão de 0,870 . O indicador Retorno (RET) caracteriza-se pelo retorno sobre investimento e retorno sobre ativos, que apresentou intervalo de 3 e 5, portanto, a maior média dos indicadores, com 4,50, e desvio padrão de 0,712 . Quatro medidas tradicionais financeiras foram utilizadas para o indicador Financeiro (FIN): lucro/lucro líquido, vendas, variações no orçamento e metas financeiras. No intervalo de 1 a 5 , esse indicador obteve a segunda melhor média, com 4,19, e desvio padrão de 0,787 .

A importância do uso de indicadores tradicionais e/ou não tradicionais como medidas de desempenho pode estar relacionado com particularidades de cada empresa, o que implica mais pesquisas. Ressalvado o escopo da pesquisa, Beuren, Kaveski e Rigo (2014) constaram que o uso de medidas não financeiras e de recursos humanos em empresas dependentes de capital humano está relacionado com estrutura de remuneração dos executivos. Também Aguiar e Frezatti (2014) observaram associação entre o 
Relação da Importância dos Recursos Estratégicos com as Medidas de Desempenho em Empresas Brasileiras

uso de medidas não financeiras de desempenho e a orientação temporal dos gestores, se mais de curto ou de longo prazo.

Em relação ao Bloco $\mathrm{B}$, que compreende os recursos estratégicos, foram realizados sete questionamentos aos gestores, distribuídos em três grupos de indicadores de capital (Capital Humano, Capital Estrutural e Capital Físico). O Capital Humano (CH) contou com a primeira pergunta relativa a importância do próprio capital humano, como recurso estratégico, e o conhecimento dos clientes. O intervalo apresentado foi de 3 e 5 , com média de 4,24, sendo a maior do grupo, e um desvio padrão de 0,704. O Capital Estrutural (CE) é definido como o conhecimento agregado pelos funcionários e contou com três perguntas, a saber: estado da arte/instalações, novas tecnologias, patentes e outros tipos de ativos. $\mathrm{O}$ intervalo foi de 1 e 5, com a segunda melhor média, 3,47, e um desvio padrão de 1,201. Por último, o Capital Físico (CF) foi constituído pela dispersão geográfica das unidades e outros ativos fixos. Os intervalos foram de 2 e 5, com média de 3,21 e desvio padrão de 1,120 .

A estatística descritiva mostrou que os gestores atribuem maior importância ao Capital Humano (média de 4,24) e menor importância ao
Capital Físico (média de 3,21). Esse resultado coaduna com os estudos de Kaplan e Norton (1996), IFAC (1998), Stivers et al. (1998) e Lev (2001), que apontaram que a economia passou de uma economia voltada ao capital físico para uma economia atrelada ao capital intelectual. Por outro lado, coaduna com o observado na pesquisa de Pedrosa e Carvalho (2014), que a vantagem competitiva tem importante papel nos processos de exploração da combinação de recursos com capacidades.

Em síntese, para os 15 indicadores de desempenho utilizados na pesquisa, a maioria indicou valores superiores da escala, o que sugere graus elevados de importância, especialmente nos indicadores relativos ao desempenho dos empregados e ao retorno, em que a maioria atribuiu notas 3 ou 4, na escala de 5 pontos. Já nos sete indicadores de recursos estratégicos, as indicações estão distribuídas na escala entre os valores 2 e 5 , caracterizando também haver importância de acordo com os respondentes.

\subsection{Análise de correlação das variáveis}

Com base nas hipóteses formuladas, apresenta-se na Tabela 2 a correlação de Spearman dos recursos estratégicos com as medidas de desempenho.

Tabela 2 - Análise de correlação das variáveis

\begin{tabular}{|l|c|c|c|c|c|c|c|c|}
\hline & CH & CE & CF & EMP & FIN & OP & RET & PROD \\
\hline CH & 1 & & & & & & & \\
\hline CE & $-0,265$ & 1 & & & & & & \\
\hline CF & $-0,489$ & 0,274 & 1 & & & & & \\
\hline EMP & $\mathbf{0 , 2 7 9}$ & 0,083 & 0,162 & 1 & & & & \\
\hline FIN & $-0,070$ & $\mathbf{0 , 2 5 2}$ & $\mathbf{0 , 3 2 9}$ & $\mathbf{0 , 2 1 8}$ & 1 & & & \\
\hline OP & $-0,192$ & $\mathbf{0 , 3 9 1}$ & 0,109 & 0,131 & $\mathbf{0 , 3 7 0}$ & 1 & & \\
\hline RET & $\mathbf{0 , 4 2 9}$ & $-0,236$ & $-0,477$ & $\mathbf{0 , 3 1 7}$ & 0,174 & $-0,074$ & 1 & \\
\hline PROD & 0,088 & $-0,080$ & 0,008 & $-0,102$ & $-0,190$ & $-0,089$ & $-0,314$ & 1 \\
\hline
\end{tabular}

Obs.: Os valores em negrito são os que resultaram estatisticamente significativos ao nível de $95 \%$.

Fonte: dados da pesquisa.

A hipótese de pesquisa $\mathrm{H} 1$ verifica se há associação significativa positiva entre a avaliação dos gestores da importância dada pela empresa aos recursos estratégicos e o desempenho da empresa. Verifica-se que há uma relação positiva maior entre o recurso estratégico Capital Físico (CF) com a maioria dos indicadores de desempenho. No entanto, a hipótese não foi confirmada, pois somente a variável Financeiro (FIN) $(0,329)$ atingiu a significância esperada. A subhipótese H1a também não foi confirmada, uma vez que constatou-se uma associação tênue entre o recurso estratégico Capital Humano $(\mathrm{CH})$ e as medidas de desempenho, e o mesmo ocorreu com o recurso Capital Estrutural (CE).
Observa-se uma associação significativa entre a avaliação dos gestores da importância do uso de certos tipos de medidas de desempenho e a sua avaliação da importância dada pela empresa aos diversos recursos estratégicos, conforme estabelecido na H2. As correlações apresentaram-se positivas, demonstrando a importância destes indicadores para a empresa. No entanto, constatou-se uma forte associação entre a avaliação dos gestores da importância dada pela empresa ao capital humano e a importância do uso de medidas de retorno (RET). A relação desse capital com as medidas não tradicionais, Empregado (EMP), Operacional (OP) e Produtividade (PROD), foi confirmada somente para a variável 
Relação da Importância dos Recursos Estratégicos com as Medidas de Desempenho em Empresas Brasileiras

Empregado (EMP), confirmando-se, assim, parcialmente a hipótese $\mathrm{H} 2 \mathrm{a}$.

Foi constatada associação entre a avaliação dos gestores da importância dada pela empresa ao capital estrutural e a sua avaliação da importância do uso de medidas não tradicionais, mas somente para a variável Operacional (OP). Desse modo, a relação do Capital Estrutural (CE) com as variáveis não tradicionais, a que se propunha na hipótese $\mathrm{H} 2 \mathrm{~b}$, foi confirmada parcialmente. Os dados revelaram a existência de uma forte associação entre a avaliação dos gestores da importância dada pela empresa ao capital físico e sua avaliação da importância do uso de medidas tradicionais, em específico Financeiras (FIN). A relação do Capital Físico (CF) com a variável Financeiro (FIN) apresentou o coeficiente de 0,329, indicando uma forte relação entre as variáveis, confirmando a hipótese $\mathrm{H} 2 \mathrm{c}$.

Por último, observou-se que a avaliação dos gestores da importância do uso de medidas de desempenho medeia significativamente a relação entre as crenças dos gestores sobre a importância dos recursos estratégicos e o desempenho da empresa (H3).
Para as empresas, o mais forte efeito indireto sobre o desempenho é a avaliação dos gestores da importância dada pela empresa ao capital humano, mediada pela avaliação dos gestores da importância do uso de medidas não tradicionais (EMP), conforme proposto na hipótese H3a. No entanto, não houve confirmação da relação entre o capital humano e as medidas operacionais, que se apresentaram negativas.

\subsection{Análise comparativa com o estudo de Widener (2006)}

$\mathrm{Na}$ Tabela 3 evidencia-se uma análise comparativa da estatística descritiva dos resultados da pesquisa de Widener (2006) e os observados neste estudo. Ressalta-se, no entanto, que há necessidade de parcimônia na análise comparativa, uma vez que nesta pesquisa foi utilizada a escala Likert de cinco pontos, enquanto que naquela foi utilizada a escala de sete pontos. Para fins comparativos foi realizada uma média equivalente a escala de cinco pontos nas médias do estudo de Widener (2006).

Tabela 3 - Análise comparativa da estatística descritiva dos resultados do estudo base com os observados

\begin{tabular}{|c|c|c|c|c|c|c|c|c|c|}
\hline \multirow[b]{2}{*}{ Descrição } & \multicolumn{5}{|c|}{ Resultados de Widener (2006) } & \multicolumn{4}{|c|}{ Resultados observados } \\
\hline & Mín & Máx & Média & $\begin{array}{c}\text { Média } \\
\text { Equiva } \\
1\end{array}$ & $\begin{array}{l}\text { Desvio } \\
\text { Padrão }\end{array}$ & Mín & Máx & Média & $\begin{array}{l}\text { Desvio } \\
\text { Padrão }\end{array}$ \\
\hline \multicolumn{10}{|l|}{$\begin{array}{l}\text { Bloco A: Importância do uso de medidas } \\
\text { de desempenho }\end{array}$} \\
\hline Empregado (EMP) & 1 & 7 & 3,90 & 2,78 & $\mathbf{1 , 1 7 8}$ & 1 & 5 & 3,48 & 0,621 \\
\hline Satisfação dos funcionários & 1 & 7 & 4,37 & 3,12 & 1,489 & 3 & 5 & 4,00 & 0,707 \\
\hline $\begin{array}{l}\text { Desenvolvimento de competências dos } \\
\text { empregados }\end{array}$ & 1 & 7 & 4,20 & 3,00 & 1,270 & 3 & 4 & 3,41 & 0,507 \\
\hline Turnover voluntário & 1 & 7 & 3,93 & 2,81 & 1,458 & 3 & 4 & 3,18 & 0,393 \\
\hline Dias de treinamento por empregado & 1 & 7 & 3,67 & 2,62 & 1,399 & 3 & 5 & 4,00 & 0,612 \\
\hline $\begin{array}{l}\text { Número de planos de desenvolvimento } \\
\text { pessoal concluídos concluídos }\end{array}$ & 1 & 7 & 3,32 & 2,37 & 1,477 & 1 & 4 & 2,82 & 0,883 \\
\hline Operacional (OP) & 1 & 7 & 3,58 & 2,55 & 1,439 & 1 & 5 & 3,28 & 0,928 \\
\hline Vendas de novos produtos ou serviços & 1 & 7 & 4,42 & 3,16 & 1,822 & 2 & 5 & 3,06 & 1,144 \\
\hline Ciclo ou lead time & 1 & 7 & 4,07 & 2,91 & 1,880 & 3 & 5 & 4,47 & 0,624 \\
\hline Número de patentes & 1 & 7 & 2,26 & 1,61 & 1,787 & 1 & 4 & 2,18 & 1,015 \\
\hline Produtividade (PROD) & 1 & 7 & 4,25 & 3,04 & 1,683 & 2 & 4 & 3,41 & $\mathbf{0 , 8 7 0}$ \\
\hline Vendas /custo da mão de obra & 1 & 7 & 4,25 & 3,04 & 1,683 & 2 & 4 & 3,41 & 0,870 \\
\hline Retorno (RET) & 2 & 7 & 4,99 & 3,56 & 1,282 & 3 & 5 & 4,50 & 0,712 \\
\hline Retorno sobre investimento & 2 & 7 & 5,15 & 3,68 & 1,439 & 3 & 5 & 4,59 & 0,712 \\
\hline Retorno sobre ativos & 2 & 7 & 4,82 & 3,44 & 1,393 & 3 & 5 & 4,41 & 0,712 \\
\hline Financeiras (FIN) & 1,5 & 7 & 5,79 & 4,13 & 1,911 & 1 & 5 & 4,19 & $\mathbf{0 , 7 8 7}$ \\
\hline Lucro/Lucro Líquido & 1 & 7 & 6,39 & 4,56 & 1,164 & 3 & 5 & 4,41 & 0,712 \\
\hline Vendas & 2 & 7 & 5,77 & 4,12 & 1,271 & 4 & 5 & 4,59 & 0,507 \\
\hline Variações no Orçamento & 1 & 7 & 5,21 & 3,72 & 1,206 & 1 & 5 & 3,59 & 1,121 \\
\hline Metas Financeiras & 1 & 7 & 5,79 & 4,14 & 1,079 & 3 & 5 & 4,18 & 0,809 \\
\hline $\begin{array}{l}\text { Bloco B: Importância dos recursos } \\
\text { estratégicos }\end{array}$ & & & & & & & & & \\
\hline
\end{tabular}


Relação da Importância dos Recursos Estratégicos com as Medidas de Desempenho em Empresas Brasileiras

\begin{tabular}{|l|c|c|c|c|c|c|c|c|c|}
\hline Capital humano (CH) & $\mathbf{1}$ & $\mathbf{7}$ & $\mathbf{5 , 4 5}$ & $\mathbf{3 , 8 9}$ & $\mathbf{1 , 4 2 0}$ & $\mathbf{3}$ & $\mathbf{5}$ & $\mathbf{4 , 2 4}$ & $\mathbf{0 , 7 0 4}$ \\
\hline Capital humano & 1 & 7 & 5,34 & 3,81 & 1,492 & 3 & 5 & 4,29 & 0,772 \\
\hline Conhecimento dos clientes & 1 & 7 & 5,57 & 3,98 & 1,711 & 3 & 5 & 4,18 & 0,636 \\
\hline Capital estrutural (CE) & $\mathbf{1 , 6 7}$ & $\mathbf{7}$ & $\mathbf{4 , 0 4}$ & $\mathbf{2 , 8 9}$ & $\mathbf{1 , 2 4 1}$ & $\mathbf{1}$ & $\mathbf{5}$ & $\mathbf{3 , 4 7}$ & $\mathbf{1 , 2 0 1}$ \\
\hline Estado da Arte/instalações & 1 & 7 & 3,95 & 2,82 & 1,538 & 2 & 5 & 3,59 & 1,004 \\
\hline Novas tecnologias & 1 & 7 & 5,04 & 3,60 & 1,535 & 2 & 5 & 3,82 & 1,185 \\
\hline Patentes e outros tipos de ativos & 1 & 7 & 3,14 & 2,24 & 2,039 & 1 & 5 & 3,00 & 1,414 \\
\hline Capital físico (CF) & $\mathbf{1}$ & $\mathbf{6 . 5}$ & $\mathbf{3 , 8 5}$ & $\mathbf{2 , 7 5}$ & $\mathbf{1 , 3 0 9}$ & $\mathbf{2}$ & $\mathbf{5}$ & $\mathbf{3 , 2 1}$ & $\mathbf{1 , 1 2 0}$ \\
\hline Dispersão geográfica das unidades & 1 & 7 & 3,83 & 2,74 & 1,871 & 2 & 5 & 3,41 & 1,121 \\
\hline Outros ativos fixos & 1 & 7 & 3,86 & 2,76 & 1,657 & 2 & 5 & 3,00 & 1,118 \\
\hline
\end{tabular}

Fonte: dados da pesquisa.

Nota-se na Tabela 3 que em relação à importância do uso de medidas de desempenho quanto ao empregado, do Bloco A, verifica-se que não há proximidade entre a média apurada na presente pesquisa e a média equivalente da pesquisa de Widener (2006). Na média os valores não se apresentaram semelhantes, sendo 2,78 e 3,48 respectivamente para Widener (2006) e esta pesquisa. Todas as variáveis da medida de desempenho Empregados (EMP) obtiveram média equivalente menor na pesquisa de Widener (2006) em relação as médias do presente estudo.

Na medida de desempenho Operacional (OP), a média equivalente foi de 2,55 na pesquisa de Widener (2006) e 3,28 neste estudo. A única variável que obteve média equivalente superior nesta categoria foi "Vendas de novos produtos ou serviços", com média de 3,16 na pesquisa de Widener (2006) contra uma média de 3,06 neste estudo. $\mathrm{Na}$ medida de desempenho Produtividade (PROD) as médias de ambas as pesquisas não ficaram muito distantes, com média equivalente de 3,04 em Widener (2006) e 3,41 nesta pesquisa.

A medida de desempenho Retorno (RET) apresentou a maior discrepância entre as médias, de 3,56 na pesquisa de Widener (2006) e de 4,50 nesta pesquisa. Por outro lado, as medidas de desempenho Financeiras (FIN) se apresentaram bastante próximas nas duas pesquisas, respectivamente média equivalente de 4,13 no estudo base e média de 4,19 nesta pesquisa. $\mathrm{O}$ posicionamento extremo, Retorno (RET) com a maior diferença de médias e Financeiras (FIN) com a menor diferença de médias, instiga a realização de novos estudos, já que ambas medidas possuem características financeiras.

Quanto à importância dos recursos estratégicos para aumentar a competitividade entre as empresas (Bloco B), os resultados igualmente foram menores na pesquisa de Widener, em que o Capital Humano apresentou-se como o recurso melhor avaliado pelos gestores. Igualmente ocorreu nesta pesquisa, em que o Capital Humano mostrou-se o capital mais importante para a alavancagem da vantagem competitiva entre as empresas, segundo a opinião dos gestores respondentes do instrumento de pesquisa.
Dentre os itens indicativos de cada uma das três categorias de capitais, Estado da arte/instalações e Patentes e outros ativos, dentro do Capital Estrutural, foram os itens que apresentaram as maiores diferenças entre as médias das duas pesquisas, respectivamente com 2,82 e 2,24 no estudo base e 3,59 e 3,00 nesta pesquisa, demonstrando a atribuição de menor importância para estas variáveis nas empresas pesquisadas por Widener (2006).

De modo geral, na análise comparativa dos resultados destaca-se que em apenas três variáveis (Vendas de novos produtos ou serviços, Lucro/Lucro Líquido e Variações no orçamento) a pesquisa de Widener (2006) apresentou médias equivalentes superiores em relação aos apurados neste estudo, porém, com variações pequenas entre as médias (de $0,10$ a 0,15$)$. Ressalta-se também que as medidas de desempenho Financeira (FIN) e Capital Humano (CH) apresentaram as maiores médias em ambas as pesquisas, o que parece contraditório, já que era de se esperar que maior importância dada para capital humano implicaria maior importância do uso de indicadores não financeiros.

No Quadro 2 faz-se um comparativo da síntese entre os achados neste estudo, relativos as hipóteses, com os resultados do estudo base. 
Relação da Importância dos Recursos Estratégicos com as Medidas de Desempenho em Empresas Brasileiras

\begin{tabular}{|c|c|c|c|}
\hline $\mathbf{N}^{\circ}$ & Descrição das hipóteses & $\begin{array}{c}\text { Resultados de } \\
\text { Widener (2006) }\end{array}$ & $\begin{array}{r}\text { Resultados } \\
\text { observados }\end{array}$ \\
\hline H1 & $\begin{array}{l}\text { Há uma associação significativa positiva entre avaliação dos gestores da } \\
\text { importância dada pela empresa aos diversos recursos estratégicos e o } \\
\text { desempenho. }\end{array}$ & $\begin{array}{l}\text { Confirmada } \\
\text { parcialmente }\end{array}$ & $\begin{array}{c}\text { Não } \\
\text { confirmada }\end{array}$ \\
\hline H1a & $\begin{array}{l}\text { A associação entre a importância dada ao capital humano e o } \\
\text { desempenho é mais forte do que as associações entre a importância } \\
\text { atribuída a outros recursos estratégicos (capital físico e capital estrutural) } \\
\text { e o desempenho. }\end{array}$ & Confirmada & $\begin{array}{c}\text { Não } \\
\text { confirmada }\end{array}$ \\
\hline $\mathrm{H} 2$ & $\begin{array}{l}\text { Há uma associação significativa positiva entre a avaliação dos gestores } \\
\text { da importância do uso de certos tipos de medidas de desempenho e a sua } \\
\text { avaliação da importância dada pela empresa aos diversos recursos } \\
\text { estratégicos. }\end{array}$ & Confirmada & $\begin{array}{c}\text { Não } \\
\text { confirmada }\end{array}$ \\
\hline $\mathrm{H} 2 \mathrm{a}$ & $\begin{array}{l}\text { Há uma associação mais forte entre a avaliação dos gestores da } \\
\text { importância dada pela empresa ao capital humano e a sua avaliação da } \\
\text { importância do uso de medidas não tradicionais (empregado, } \\
\text { produtividade e medidas operacionais), do que com a sua avaliação da } \\
\text { importância do uso de medidas tradicionais. }\end{array}$ & Não confirmada & $\begin{array}{l}\text { Confirmada } \\
\text { parcialmente }\end{array}$ \\
\hline $\mathrm{H} 2 \mathrm{~b}$ & $\begin{array}{l}\text { Há uma associação mais forte entre a avaliação dos gestores da } \\
\text { importância dada pela empresa ao capital estrutural e a sua avaliação da } \\
\text { importância das medidas não tradicionais (empregado, produtividade e } \\
\text { medidas operacionais), do que com a sua avaliação da importância do } \\
\text { uso de medidas tradicionais. }\end{array}$ & Confirmada & $\begin{array}{l}\text { Confirmada } \\
\text { parcialmente }\end{array}$ \\
\hline $\mathrm{H} 2 \mathrm{c}$ & $\begin{array}{l}\text { Há uma associação mais forte entre a avaliação dos gestores da } \\
\text { importância dada pela empresa ao capital físico e sua avaliação da } \\
\text { importância do uso de medidas tradicionais, do que com a sua avaliação } \\
\text { da importância do uso de medidas não tradicionais (empregado, } \\
\text { produtividade e medidas operacionais). }\end{array}$ & $\begin{array}{l}\text { Confirmada } \\
\text { parcialmente }\end{array}$ & Confirmada \\
\hline $\mathrm{H} 3$ & $\begin{array}{l}\text { A avaliação dos gestores da importância do uso de medidas de } \\
\text { desempenho medeia significativamente a relação entre as crenças dos } \\
\text { gestores sobre a importância dos recursos estratégicos e o desempenho } \\
\text { da empresa. }\end{array}$ & Confirmada & Confirmada \\
\hline $\mathrm{H} 3 \mathrm{a}$ & $\begin{array}{l}\text { O mais forte efeito indireto sobre o desempenho é a avaliação dos } \\
\text { gestores da importância dada pela empresa ao capital humano, mediada } \\
\text { pela avaliação dos gestores da importância do uso de medidas não } \\
\text { tradicionais. }\end{array}$ & Confirmada & Confirmada \\
\hline
\end{tabular}

Quadro 2 - Comparativo dos resultados das hipóteses do estudo base com os deste estudo Fonte: dados da pesquisa.

Observa-se no Quadro 2 que no estudo de Widener (2006) foram confirmadas as hipóteses H1a, $\mathrm{H} 2, \mathrm{H} 2 \mathrm{~b}, \mathrm{H} 3$ e $\mathrm{H} 3 \mathrm{a}$; confirmadas parcialmente as hipóteses $\mathrm{H} 1$ e $\mathrm{H} 2 \mathrm{c}$; e não confirmada foi apenas a hipótese H2a. Na presente pesquisa observa-se as três primeiras hipóteses não confirmadas, as duas seguintes parcialmente confirmadas $\mathrm{e}$ as três últimas confirmadas. Portanto, o resultado de ambas as pesquisas foi convergente apenas nas hipóteses $\mathrm{H} 3$ e $\mathrm{H} 3 \mathrm{a}$, pois em ambas as pesquisas essas hipóteses foram confirmadas.

A não confirmação das três primeiras hipóteses nesta pesquisa indica que na avaliação dos gestores não prevalece maior importância atribuída ao capital humano e o desempenho em comparação a importância atribuída a outros recursos estratégicos (capital físico e capital estrutural) e o desempenho. Isto indica que, diferente das empresas pesquisadas por Widener (2006), nesta pesquisa observa-se que são consideradas diversas medidas (tradicionais e não tradicionais) na avaliação de desempenho dos gestores.

A confirmação da hipótese $\mathrm{H} 2 \mathrm{c}$ denota a situação acima apontada e até a coerência de considerar também indicadores tradicionais, pois foi observada associação mais forte na avaliação dos gestores da importância dada pela empresa ao capital físico por meio do uso de medidas tradicionais, do que com medidas não tradicionais (empregado, produtividade e medidas operacionais). Todavia, a confirmação da duas últimas hipóteses neste estudo indica, de modo semelhante a pesquisa de Widener (2006), que a importância estratégica do capital humano está associada positivamente com o desempenho empresarial.

De acordo com as respostas dos gestores, corrobora-se o preconizado por Stewart (1998), de que empresas que atribuem importância ao capital humano 
e escolhem medidas de desempenho de Empregado (EMP) irão obter um desempenho significativamente superior em relação às outras empresas. Depreende-se que nestas empresas há preocupação dos gestores nesse sentido, uma vez que atribuem maior importância na relação dos recursos estratégicos com medidas não tradicionais de desempenho do que com medidas tradicionais.

\section{CONCLUSÕES}

Este estudo objetivou verificar se as medidas de desempenho são variáveis mediadoras entre a importância dos recursos estratégicos e a avaliação de desempenho em empresas brasileiras. De modo específico buscou investigar a percepção dos gestores quanto à importância atribuída às medidas de desempenho tradicionais e não tradicionais e aos recursos estratégicos de capital humano, estrutural e físico em empresas brasileiras. Fundamentado na pesquisa de Widener (2006) em empresas norteamericanas, realizou-se um levantamento em empresas listadas na BM\&FBovespa nos níveis 1 e 2 de Governança Corporativa. A população constou de 57 empresas e a amostra por acessibilidade compreendeu as 17 empresas que retornaram o questionário respondido.

Os resultados mostram que os gestores atribuem importância às diversas medidas de desempenho, tradicionais e não tradicionais, apresentadas no instrumento de pesquisa. Porém, a estatística descritiva evidencia que a maior importância é atribuída às medidas tradicionais, tanto de retorno (retorno sobre investimento e retorno sobre ativos) como financeiras (lucro/lucro líquido, vendas, variações no orçamento e metas financeiras), tal qual os achados de Widener (2006).

Dentre os recursos estratégicos analisados, os gestores respondentes da pesquisa conferiram maior importância ao capital humano, seguido do capital estrutural e do capital físico. Os gestores confirmaram a importância de tal recurso para o crescimento empresarial, tal qual o estudo de Widener (2006). O capital humano é, portanto, o recurso mais utilizado pelas empresas para sustentar sua vantagem competitiva no mercado, tendo em vista que são as pessoas que fazem com que as medidas de desempenho sejam suplantadas.

$\mathrm{Na}$ análise de correlação entre as variáveis dos recursos estratégicos e as variáveis de medidas de desempenho, constatou-se haver relação positiva entre as mesmas. No entanto, os recursos estratégicos relacionaram-se mais fortemente com as medidas tradicionais de desempenho, apesar dos gestores atribuírem maior importância ao capital humano do que ao capital estrutural e físico. É possível que a pequena amostra da pesquisa possa estar influenciando estes resultados, por isso os achados devem ser considerados com parcimônia.

Em relação às hipóteses levantadas, $\mathrm{H} 1, \mathrm{H} 1 \mathrm{a}$ e $\mathrm{H} 2$ não foram confirmadas. As hipóteses $\mathrm{H} 2 \mathrm{a}$ e $\mathrm{H} 2 \mathrm{~b}$ foram confirmadas parcialmente. Apesar da maioria das variáveis apresentarem relações positivas, não foram significativas o bastante para a confirmação total dessas hipóteses. As hipóteses H2c, H3 e H3a foram confirmadas, ou seja, na avaliação dos gestores, a importância do uso de medidas de desempenho medeia significativamente os recursos estratégicos e o desempenho da empresa, tendo o mais forte efeito indireto sobre o desempenho a avaliação dos gestores da importância dada pela empresa ao capital humano.

$\mathrm{Na}$ análise comparativa da estatística descritiva, os gestores na pesquisa de Widener (2006) atribuíram maior importância para o uso de medidas de desempenho financeiras, assim como neste estudo, seguido da importância atribuída às medidas de retorno. Quanto à importância atribuída pelos gestores aos recursos estratégicos para manter a vantagem competitiva, tanto na pesquisa de referência como no presente estudo observa-se maior importância conferida ao capital humano, seguido do capital estrutural e do capital físico.

No comparativo dos resultados das hipóteses levantadas por Widener (2006), naquele estudo mostraram-se positivas e algumas significativas. No presente estudo, algumas hipóteses não foram confirmadas (H1, H1a e H2), outras hipóteses foram confirmadas parcialmente ( $\mathrm{H} 2 \mathrm{a}$ e $\mathrm{H} 2 \mathrm{~b})$ e três hipóteses apresentaram-se positivas e significativas $(\mathrm{H} 2 \mathrm{c}, \mathrm{H} 3 \mathrm{e}$ $\mathrm{H} 3 \mathrm{a})$. As diferenças nos resultados de ambas as pesquisas podem decorrer de diferenças culturais, ou seja, empresas norte-americanas e empresas brasileiras. No entanto, outros fatores podem ter contribuído, o que instiga a realização de novos estudos.

A partir das relações estabelecidas no estudo base e aplicadas neste estudo, conclui-se que as medidas de desempenho são variáveis mediadoras entre a avaliação dos gestores da importância dada pela empresa aos recursos estratégicos e o desempenho. O estudo de Widener (2006) mostrou a importância dos recursos estratégicos para as empresas que buscam vantagem competitiva no mercado, bem como a importância de se avaliar o desempenho empresarial por meio de indicadores confiáveis. Em empresas brasileiras, consideradas suas peculiaridades, pode-se encontrar resultados que sugerem algumas semelhantes com os resultados apurados por Widener (2006).

Os resultados do estudo requerem parcimônia na sua interpretação, em vista das limitações desta pesquisa, em especial o tamanho da amostra, que não permitiu a separação dos dados de empresas manufatureiras e não manufatureiras e que inviabilizou a aplicação da modelagem de equações estruturais, como realizado no estudo base. Outro aspecto a ser considerado é que os resultados não podem ser extrapolados para além dos recursos estratégicos e os indicadores de desempenho investigados. Desse modo, recomenda-se para futuras 
pesquisas ampliar o universo de empresas pesquisadas e aprofundar os estudos em novos indicadores de desempenho, confrontando-os com outros recursos estratégicos utilizados pelas organizações.

\section{REFERÊNCIAS}

Aguiar, A. B., \& Frezatti, F. (2014). Uso de medidas não financeiras de desempenho, estratégia e orientação temporal de gestores das 'Melhores Empresas para Você Trabalhar'. REAd. Revista Eletrônica de Administração (Porto Alegre. Online), 77(1) 114-139.

Amit, R., \& Schoemaker, P. J. H. (1993). Strategic assets and organizational rent. Strategic Management Journal, 14(1), 33-46.

Baines, A., \& Langfield-Smith, K. (2003). Antecedents to management accounting change: a structural equation approach. Accounting, Organizations and Society, 28(7/8), 675-698.

Barney, J. (1991). Firm resources and sustained competitive advantage. Journal of Management, 17(1), 99-120.

Barney, J. B. (2001). Is the resource-based view a useful perspective for strategic management research? Yes. Academy Management Review, 26(1), 41-56.

Beuren, I. M., Kaveski, I. D. S., \& Rigo, V. P. (2014). Associação das medidas de desempenho para pagamento de bônus aos executivos com dependência de capital humano. Revista Contemporânea de Contabilidade, 11(22), 03-24.

Beyan, O. D., \& Baykal, N. (2012). A knowledge based search tool for performance measures in health care systems. Journal of Medical Systems, 36(1), 201-221.

Bharadwaj, S. G., Varadarajan, P. R., \& Fahy, J. (1993). Sustainable competitive advantage in service industries: a conceptual model and research propositions. Journal Mark, 57(4), 83-99.

Bourne, M., Neely, A. D., Mills, J. F., Platts, K., \& Wilcox, M. (2000). Designing, implementing and updating performance measurement systems. International Journal of Operations \& Production Management, 20(7), 754-771.

Brancato, C. K. (1995). New performance measures: a research report. The Conference Board, Report n. 1118-95-RR.

Callado, A. A. C., Callado, A. L. C., Moller, H. D., \&
Neutzling, D. M. (2009). Indicadores de desempenho social corporativo: um estudo entre empresas do setor elétrico. eGesta, 5(1), 71-93.

Coleman, J. S. (1988). Social capital in the creation of human capital. The American Journal of Sociology, 94(1), S95-S120.

Corrêa, H. L., \& Hourneaux Junior, F. (2008). Sistemas de mensuração e avaliação de desempenho organizacional: estudo de casos no setor químico no Brasil. Revista de Contabilidade \& Finanças USP, 19(48), 50-64.

Drickhamer, D. (2002). Next generation performance measurement. Industry Week, 251(6), 14.

Edvinsson, L., \& Malone, M. S. (1998). Capital intelectual: descobrindo o valor real de sua empresa pela identificação de seus valores internos. São Paulo: Makron Books.

Edwards, D. (1997). Toward a discursive psychology of classroom education. In: Coll, C., \& Edwards, D. (Eds.). Teaching, learning and classroom discourse: approaches to the study of educational discourse (p. 33-48). Madrid: Fundación Infancia y Aprendizaje.

Gil, A. C. (2002). Como elaborar projetos de pesquisa (4 ed.). São Paulo: Atlas.

Godoy, A. L. (s/d). Indicadores de desempenho organizacional. Disponível em: $<$ http://www.cedet.com.br/index.php?/Tutoriais/Ge stao-da-Qualidade/indicadores-de-desempenhoorganizacional.html>. Acesso em: 15 mar. 2012.

Gonçalves, J. P. (2002). Desempenho organizacional. Seminário Econômico, n. 815.

Hair Jr., J. F., Babin, B., Money, A. H., \& Samouel, P. (2005). Fundamentos de métodos de pesquisa em administração. Porto Alegre: Bookman.

Hughes, P., \& Morgan, R. E. (2008). Fitting strategic resources with product-market strategy: performance implications. Journal of Business Research, 61(4), 323-331.

Hunt, S. D. (2000). A general theory of competition. Thousand Oaks, CA: Sage.

International Federation of Accountants (IFAC). (1998). The measurement and management of intellectual capital: an introduction. New York: Report.

Ittner, C. D., \& Larcker, D. L. (1995). Total quality management and the choice of information and 
Relação da Importância dos Recursos Estratégicos com as Medidas de Desempenho em Empresas Brasileiras

reward systems. Journal of Accounting Research, $33(1), 1-34$.

Kaplan, R. S., \& Norton, D. P. (1996). The Balanced Scorecard. Boston, MA: Harvard Business School Press.

Lev, B. (2001). Intangibles: management, measurement and reporting. Washington, D.C.: Brookings Institution Press.

Luo, X., Sivakumar K., \& Liu, S. S. (2005). Globalization, marketing resources, and performance: evidence from China. Journal Academy Mark Sci, 33(1), 50-65.

Macarthur, J. B. (1996). Performance measures that count: monitoring variables of strategic importance. Journal of Cost Management, 10(3), 39-45.

Martins, R. (2004). Sistemas de medição de desempenho: um modelo para estruturação do uso. Tese de Doutorado, Universidade de São Paulo, São Paulo, SP, Brasil.

Mia, L., \& Clarke, B. (1999). Market competition, management accounting systems and business unit performance. Management Accounting Research, 10(2), 137-158.

Muller, C. J. (2003). Modelo de gestão integrando planejamento estratégico, sistemas de avaliação de desempenho e gerenciamento de processos. Tese de Doutorado, Universidade Federal do Rio Grande do Sul, Porto Alegre, RS, Brasil.

Neely, A., \& Gregory, M. (1995). Performance measurement system design. International Journal of Operations \& Producy Management, 15(4), 80116.

Paiva,V. (2001). Sobre o conceito de capital humano. Cadernos de Pesquisa, (113), 185-191.

Pedrosa, A. J. P. \& Carvalho, F. M. P. O. (2014). Análise dos fundamentos da Teoria Baseada nos Recursos. Revista Ibero-Americana de Estratégia RIAE, 13(2), 10-24.Phatak, A. A. (1995). International dimensions of management (4 ed.). Cincinnati, OH: South-Western College Publishers.
Raupp, F. M., \& Beuren, I. M. (2006). Metodologia da pesquisa aplicável às ciências sociais. In. Beuren, I. M. (Org). Como elaborar trabalhos monográficos em contabilidade (3 ed.. São Paulo: Atlas.

Richardson, R. J. (1999). Pesquisa social: métodos e técnicas (3 ed.). São Paulo: Atlas.

Rummler, G. A., \& Brache A. P. (1994). Melhores desempenhos das empresas: uma abordagem prática para transformar as organizações através da reengenharia. São Paulo: Makron Books.

Salterio, S., \& Webb, A. (2003). The balanced scorecard. CA Magazine, 136(6), 39.

Schultz, T. W. (1962). O valor econômico da educação. Rio de Janeiro: Zahar.

Sellitto, M. A., Borchardt M., \& Pereira, G. M. (2006). Avaliação multicriterial de desempenho: um estudo de caso na indústria de transporte coletivo. Gestão \& Produção, 13(2), 339-352.

Simons, R. (2000). Performance measurement and control systems for implementing strategy. Upper Saddle River, NJ: Prentice Hall.

Stewart, T. A. (1998). Capital intelectual: a nova vantagem competitiva das empresas (8 ed.). Rio de Janeiro: Campus.

Stivers, B. P., Covin, T.J., Hall, N.G., \& Smalt, S.W. (1998). How nonfinancial performance measures are used. Management Accounting, 79(4), 44-49.

Vasconcelos, F. C., \& Cyrino, A. B. (2000). Vantagem competitiva: os modelos teóricos atuais e a convergência entre estratégia e teoria organizacional. RAE. Revista de Administração de Empresas, 40(4), 20-37.

Widener, S. K. (2004). An empirical investigation of the relation between the use of strategic human capital and the design of the management control system. Accounting, Organizations and Society, 29(3/4), 377-399.

Widener, S. K. (2006). Associations between strategic resource importance and performance measure use: The impact on firm performance. Management Accounting Research, 17(4), 433-457. 